\title{
Article \\ The Artificial Intelligence in Digital Radiology: Part 2: Towards an Investigation of acceptance and consensus on the Insiders
}

\author{
Francesco Di Basilio ${ }^{1}$, Gianluca Esposisto ${ }^{1}$, Lisa Monoscalco ${ }^{2}$ and Daniele Giansanti $^{3, *}$ \\ 1 Facoltà di Medicina e Psicologia, Sapienza University, Piazzale Aldo Moro, 00185 Rome, Italy; \\ fdibasilio@hotmail.com (F.D.B.); gianluca.esposito.sapienza@gmail.com (G.E.) \\ 2 Faculty of Engineering, Tor Vergata University, 00133 Rome, Italy; lisamonoscalco@hotmail.com \\ 3 Centre Tisp, Istituto Superiore di Sanità, 00161 Rome, Italy \\ * Correspondence: daniele.giansanti@iss.it; Tel.: +39-06-49902701
}

Citation: Di Basilio, F.; Esposisto, G.; Monoscalco, L.; Giansanti, D. The Artificial Intelligence in Digital Radiology: Part 2: Towards an Investigation of acceptance and consensus on the Insiders. Healthcare 2022, 10, 153. https://doi.org/ 10.3390/healthcare10010153

Academic Editor: Norbert Hosten

Received: 9 November 2021

Accepted: 10 January 2022

Published: 14 January 2022

Publisher's Note: MDPI stays neutral with regard to jurisdictional claims in published maps and institutional affiliations.

Copyright: (๑) 2022 by the authors. Licensee MDPI, Basel, Switzerland. This article is an open access article distributed under the terms and conditions of the Creative Commons Attribution (CC BY) license (https:// creativecommons.org/licenses/by/ $4.0 /)$.

\begin{abstract}
Background. The study deals with the introduction of the artificial intelligence in digital radiology. There is a growing interest in this area of scientific research in acceptance and consensus studies involving both insiders and the public, based on surveys focused mainly on single professionals. Purpose. The goal of the study is to perform a contemporary investigation on the acceptance and the consensus of the three key professional figures approaching in this field of application: (1) Medical specialists in image diagnostics: the medical specialists (MS)s; (2) experts in physical imaging processes: the medical physicists (MP)s; (3) AI designers: specialists of applied sciences (SAS)s. Methods. Participants (MSs = 92: 48 males $/ 44$ females, averaged age 37.9; MPs $=91: 43$ males $/ 48$ females, averaged age 36.1; SAS = 90: 47 males $/ 43$ females, averaged age 37.3) were properly recruited based on specific training. An electronic survey was designed and submitted to the participants with a wide range questions starting from the training and background up to the different applications of the AI and the environment of application. Results. The results show that generally, the three professionals show (a) a high degree of encouraging agreement on the introduction of AI both in imaging and in non-imaging applications using both standalone applications and/or $m$ Health/eHealth, and (b) a different consent on AI use depending on the training background. Conclusions. The study highlights the usefulness of focusing on both the three key professionals and the usefulness of the investigation schemes facing a wide range of issues. The study also suggests the importance of different methods of administration to improve the adhesion and the need to continue these investigations both with federated and specific initiatives.
\end{abstract}

Keywords: e-health; medical devices; m-health; digital-radiology; picture archive and communication system; artificial-intelligence; electronic surveys; chest CT; chest radiography; acceptance; consensus

\section{Introduction \\ Artificial Intelligence and Digital Radiology}

The standardization of digital radiology caused important changes in the field of organ and functional diagnostics. This regards both the diagnostics and the interventional radiology [1,2]. It has led to exceptional changes in the organization of work and reporting processes. Furthermore, it pushed the digitization and computerization [3,4]. This solved and simplified many organizational problems, such as the organization of the archives, even if new ones appeared, such as those related to cybersecurity [5,6]. Today, digital radiology (DR) embraces a wide sector of diagnostic scenarios, also including sectors not directly related with the ionizing radiation, such as magnetic resonance and echography [7-9]. Those imaging sectors using DICOM are united under the hat of digital radiology [10-13]. Now, we are facing the possible impact of research on the health domain [14]. An important engine in this context is represented by the research efforts during the COVID-19 pandemic. For example, research on chest $\mathrm{CT} /$ radiography has opened important discussions and scenarios [15-18]. 
AI, a field of computer science [19], when used in the health domain is considered a tool able to perform tasks normally requiring human intelligence [20-23] that in recent years have been applied in various health-related areas, such as cancer detection [24], dementia classification [25], and drug design [26], to name a few.

If we consider the potential of AI in DR, the applications are multiple.

We need to consider four important points of vieww when we enter the field of DR [27,28]:

1. A first point of view is that DR includes different imaging sectors where it can potentially be applied. If we exclude imaging processes that do not involve ionizing radiation, we can identify the following sectors, both with reference to organ and total body diagnostics:
a. Interventional radiology
b. Diagnostic radiology (radiology, CT)
c. Nuclear magnetic resonance
d. Positron emission tomography
e. amma chamber

2. A second point of view is represented by the transversal sectors that embrace these disciplines in which AI can play an important role:
a. Therapy
b. Prevention
c. Quality control
d. Risk assessment

3. A third point of view is represented by the AI app distribution methods. In fact, we must not forget that AI, in the context of DR, has a future of standardization related to software for medical devices [29]. This software has different implications if it is used standalone or on the network, and if it is networked through eHealth or mHealth solutions. The implications also concern important aspects of cybersecurity [30].

4. A fourth point of view is represented by the specific training that must include AI and also the related disciplines such as informatics, medical imaging and the technologies for biomedical app.

The passage of the AI into the routine of the DR (including the above listed points of view) must take place through an approach that provides for the transfer of evidence-based medicine (EBM) to the operational processes of the health domain, using all the available agreement tools, which include guidelines [31], technology assessment (TA) such as HTA and CER [32], and consensus conferences [33]. The latest definition of EBM, by Eddy [34], also considers the development of evidence-based policies in a multi-dimensional space of the health domain, involving quality, acceptance, consensus, and cost-effectiveness analysis. All the agreement tools will therefore also be based, as in other disciplines, on the acceptance and consensus of both the insiders and the public who will help to express important positions. A PubMed search in this area with the two keys [35,36]:

$$
\begin{aligned}
& \text { (acceptance) AND (artificial intelligence [Title/Abstract]) AND Radiology) } \\
& \text { (consensus) AND (artificial intelligence [Title/Abstract]) AND Radiology) }
\end{aligned}
$$

shows (Figure 1) 83 results, of which 77 from 2019 to today for the acceptance and 23 results for the consensus, all comprised from 2019 to today.

This means that acceptance and consensus have become a priority on this issue over the past two years. Among the emerging tools in this area, we find the surveys useful as sensors for stakeholders and managers in general. These surveys [37-47] focused on some of the actors that revolve around this area: radiologists, radiographers, primary care providers (PCP), students, and patients, that is, both on service providers and users, but also on subjects in training. The studies on patients [37-39] have highlighted the curiosity and non-opposition to these techniques, together with the need to create culture, the need to educate on the issue and the fear for the aspects of cybersecurity in integration with eHealth 
and mHealth. The students [47] showed curiosity and optimism but complained about a lack of adequate training and the need to integrate specific modules into the training programs. Openings towards these solutions have emerged from studies on radiologists and radiographers [41-46] accompanied by the strong desire to have an important role in future work-flow modification processes and adequate training. In almost all studies, with rare exceptions such as [39], free and non-standardized questionnaires were used through validation processes, indicating that scholars, at this historical moment, are relying on their creativity to create increasingly innovative and adaptive questionnaires. Instruments, such as the TAM, widely used in radiology were not used [48].

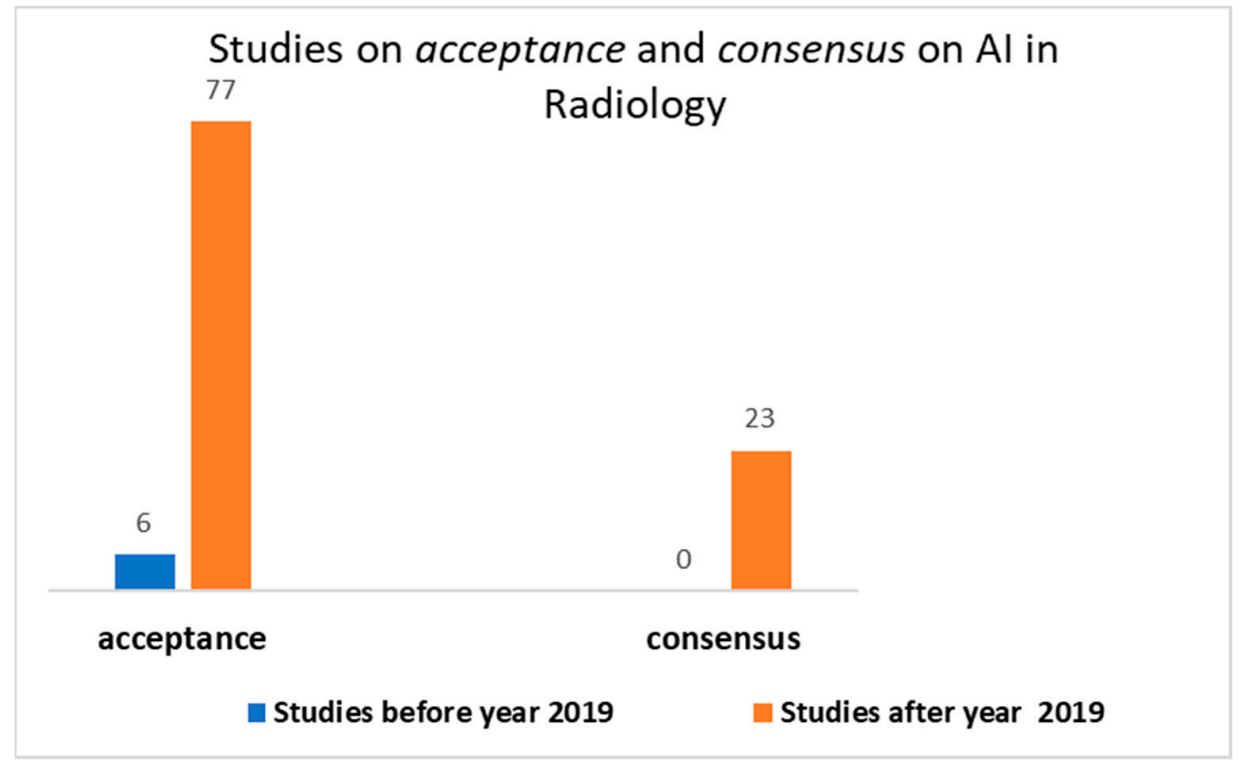

Figure 1. Output of the search on PubMed on acceptance and consensus on AI in radiology.

What emerges from these studies are the following needs of deepening for further study in the surveys. Many figures have been thought of, such as the PCP [40], but others have been neglected. No studies have been identified on the specialists of applied sciences of artificial intelligence systems. In rare cases, surveys have been carried out which involved several professional figures, such as in [44,45], which involved both radiologists and radiographers. Our hypothesis is that the AI acceptance survey in radiology:

- must consider the above-listed (1-4) points of views, not limited to imaging and including the integration into eHealth and mHealth [49];

- must consider all the involved professionals who have different training and a different work-flow and therefore different expectations from AI.

Some studies on the design and test of AI solutions are clearly highlighting the importance of the team [50]. This team comprehends (with a natural osmosis of skills):

- the medical physics;

- the medical specialist;

- the specialist in applied sciences.

A preparatory and preliminary step to the introduction of the $\mathrm{AI}$ in the clinical practice should directly face the consensus/acceptance. It emerges, based on the above, that important actors are undoubtedly (Figure 2): medical specialists $(M S)_{s}$, medical physicists $(M P)_{s}$, and specialists of applied sciences (SAS)s. MSs are a strategic role in the decision flow. MPs control the physical process. SASs design and maintain the AI tools (such as the biomedical engineers and technicians/technologists of radiology). The purpose of the study was: (a) to focus on these three professionals to investigate their acceptance and consensus; (b) to design and submit them a properly electronic survey for the investigation, with a wide range of features considering the highlighted needs of deepening the points listed above. 


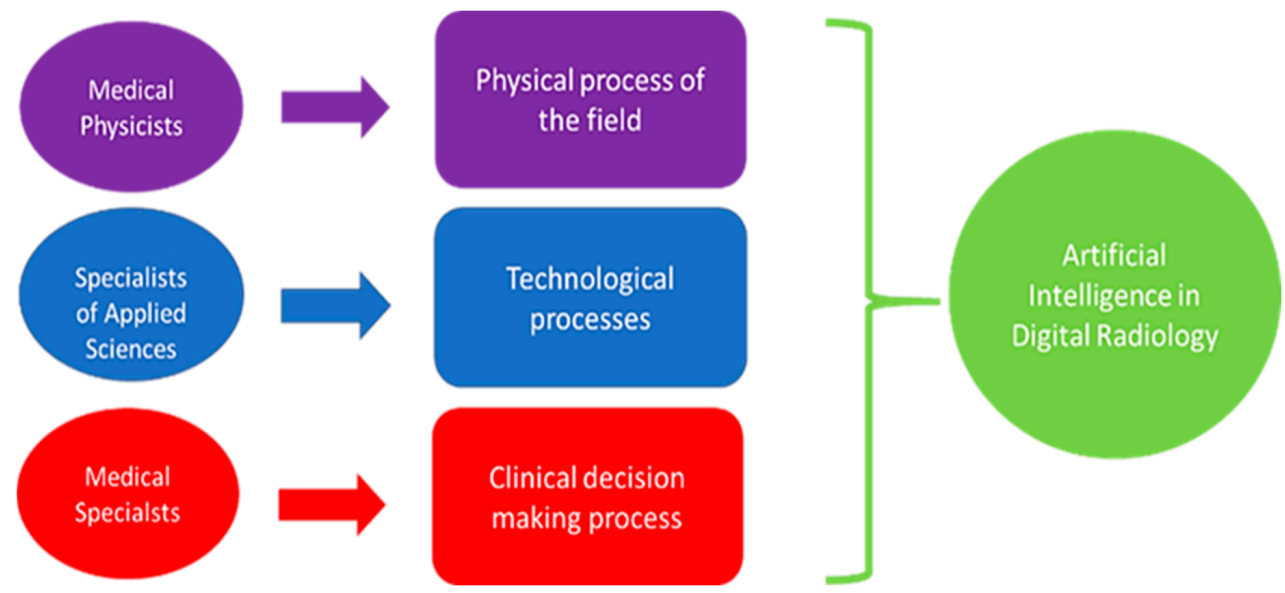

Figure 2. Interconnection among experts and AI.

\section{Methods}

In line with the aim of the study, we decided to develop a survey.

The methodology comprehended: (I) the choice of the tool for the design of the electronic survey and (II) the adequacy to regulations; (III) the design of the survey based on the chosen tool respecting the wide range features to investigate; (IV) the dissemination on a population; $(\mathrm{V})$ the data analysis based on an effective statistical approach. The questionnaire was developed using Microsoft Forms. It adhered to the SURGE Checklist [51] for the development and administration of the survey. The statistics followed two steps:

- Verification of data normality;

- Application of the ANOVA with a P lower than 0.01 for the significance of differences.

For the statistical confidence interval, we set a goal of $95 \%$.

We considered that, among the most used tests to verify the normality, there are: (a) the Shapiro-Wilk test, which is preferable for a small sample; (b) the Kolmogorov-Smirnov test, which is instead used for more numerous samples. The samples in this study are small; therefore, we used the normality test of Shapiro-Wilk. We focused on the key figures (Figure 2) for the investigation.

The electronic survey was designed to face a wide range of features (starting from the training and the background, up to the application of the AI and the environment of application) using: choice questions, open questions, graded questions, and Likert (Figure 3).

\section{Consensus/acceptance}

Personal opinions

Consensus/acceptance

in other applications of Health domain
Consensus/acceptance

on the integration into

eHealth and mHealth

\section{Features investigated by means of the electronic survey using: \\ Open questions, Choice questions, Multiple choice questions, Likerts, Graded questions.}

Figure 3. Features investigated by means of the electronic survey. 
Both in the graded questions and in the Likert questions we fixed a six-level psychometric scale; it was therefore possible to assign a minimum score of one and a maximum score of six with a theoretical mean value (TMV) of 3.5. The TMV can be referred to for comparison in the analysis of the answers. An average value of the answers below TMV indicates a more negative than positive response. An average value above TMV indicates a more positive than negative response. The survey was accompanied by a brief description of the topic that would be addressed, clearly illustrating that the focus was related to the introduction of $\mathrm{AI}$ in digital radiology.

For the recruitment, we considered the three figures as planned, who, we remember, are medical specialists (MS), medical physicists (MP), specialists of applied sciences (SAS). All figures have a different role with AI in DR; this implies a different vision/opinion/consensus. The recruitment of these figures was very complex given that they belong to very different sectors, to different scientific societies. Currently, in Italy, there are 334 scientific societies [52]. We followed two paths that we have traced:

First way

In Italy, there are also federations of scientific societies that favor a scientific osmosis between the various scientific societies.

As regards the three professionals, we referred to:

- FEDERATION OF ITALIAN MEDICAL-SCIENTIFIC SOCIETIES [53] (includes associations such as the Italian association of medical and health physics and other relevant scientific societies and other societies operating in the Medical Diagnostics and in related fields) mainly for the first two professionals MPs and MSs but also for the SASs.

- $\quad$ FEDERATION OF SCIENTIFIC AND TECHNICAL ASSOCIATIONS [54] (contains the National Group of Bioengineering and other relevant scientific societies) and FEDERATION OF SCIENTIFIC ASSOCIATIONS OF RADIOLOGY TECHNICIANS [55] (contains for example the Italian association of system administrators and telemedicine, association of interventional radiology technicians, Health Imaging Sciences Association, and other relevant societies) mainly for the SASs but also for the other professionals.

It was possible for us to have lists of congresses in which to collect preliminary adhesions of interest for the project, in the presence, with contacts, encounters, discussions. A WhatsApp group was created to which the invitation and the anonymous questionnaire were sent, with a brief description and a recall of the discussion. In this way, it was possible to send the survey anonymously.

Second way

Sending was also carried out through our networks of WhatsApp, also following a peer-to-peer mechanism.

Table 1 reports the participants, the participants agreeing to continue after opening the questionnaire, and the related demographic characteristics. The average age of those who filled out the survey was not high. This depends on the very innovative and recent typology of the proposed theme, which was more attractive and inclusive (due to the training received) for the younger population.

Table 1. Characteristics of the participants in the study and the final involvement.

\begin{tabular}{lccccc}
\hline Participants & $\begin{array}{c}\text { Participants Agreeing } \\
\text { to Continue/Passing } \\
\text { the Requirement }\end{array}$ & Males/Females & $\begin{array}{c}\text { Min Age/Max } \\
\text { Age }\end{array}$ & Mean Age \\
\hline$M S S$ & 111 & $108 / 92$ & $48 / 44$ & $32 / 43$ & 37.9 \\
$M P S$ & 105 & $97 / 91$ & $43 / 48$ & $31 / 41$ & 36.1 \\
$S A S s$ & 99 & $93 / 90$ & $47 / 43$ & $33 / 40$ & 37.3 \\
\hline
\end{tabular}

Figures A1 and A2 in the Appendix A show a sample of the questionnaire. It was converted from the Italian language into the English language. 


\section{Results}

\subsection{Outcome of the Closed Questions from the Survey}

The eS contained a specific question relating to an adequate level of knowledge on AI to participate (through the attendance, for example, of specific academic and/or postacademic training). Only those who passed this requirement were admitted to the study. The results are organized into five tables. The first table (Table 2) concerns the training on $A I$ aspects.

Table 2. Specific outcome of the perceived training.

\begin{tabular}{ccccc}
\hline Knowledge & MSs & MPs & SASs & ANOVA \\
& Score & Score & Score & $p$ \\
\hline AI (general) & 4.56 & 4.38 & 4.51 & $p>\mathbf{0 . 1}$ \\
AI (informatics) & 4.33 & 4.24 & 5.22 & $p<0.01$ \\
AI (medical imaging) & 4.98 & 5.07 & 5.02 & $p>\mathbf{0 . 1}$ \\
Technologies for biomedical Apps & 4.32 & 5.03 & 5.11 & $p<0.01$ \\
\hline
\end{tabular}

The second table (Table 3) concerns the consent/opinion on the application of AI specifically related to medical imaging.

Table 3. Specific outcome of the opinion on the application on the medical imaging.

\begin{tabular}{ccccc}
\hline Application of AI in: & MSs & MPs & SASs & \multicolumn{2}{c}{ ANOVA } \\
Score & Score & Score & p \\
\hline Interventional radiology & 4.26 & 4.18 & 4.11 & $\boldsymbol{p}>\mathbf{0 . 1}$ \\
Diagnostic radiology (radiology, CT, etc.) & 4.54 & 4.39 & 4.41 & $\boldsymbol{p}>\mathbf{0 . 1}$ \\
Nuclear magnetic resonance & 4.26 & 4.28 & 4.31 & $\boldsymbol{p}>\mathbf{0 . 1}$ \\
Positron emission tomography & 4.53 & 4.69 & 4.72 & $\boldsymbol{p}>\mathbf{0 . 1}$ \\
Gamma chamber & 4.44 & 4.38 & 4.52 & $\boldsymbol{p}>\mathbf{0 . 1}$ \\
\hline
\end{tabular}

The third table (Table 4) concerns the consent/opinion on the application on other medical aspects not directly related to medical imaging (therapy, risk analysis, quality control, prevention).

Table 4. Specific outcome of the opinion on the application of AI different from imaging.

\begin{tabular}{ccccc}
\hline $\begin{array}{c}\text { Application of AI (Non } \\
\text { Imaging) }\end{array}$ & $\begin{array}{c}\text { MSs } \\
\text { Score }\end{array}$ & $\begin{array}{c}\text { MPs } \\
\text { Score }\end{array}$ & $\begin{array}{c}\text { SASs } \\
\text { Score }\end{array}$ & $\begin{array}{c}\text { ANOVA } \\
p\end{array}$ \\
\hline Risk assessment & 4.82 & 4.21 & 4.13 & $p<0.01$ \\
Therapy & 5.21 & 4.65 & 4.52 & $p<0.01$ \\
Prevention & 5.11 & 4.02 & 4.11 & $p<0.01$ \\
Quality Control & 4.12 & 5.07 & 5.12 & $p<0.01$ \\
\hline
\end{tabular}

The fourth table (Table 5) concerns aspects on how it is considered convenient to approach AI regarding the information available (eHealth, $m$ Health, Standalone, both $e$ Health and $m$ Health) [43].

Table 5. Specific outcome of the opinion on the use/delivery of the AI.

\begin{tabular}{ccccc}
\hline Scheme & MSs & MPs & SASs & ANOVA \\
& Score & Score & Score & p \\
\hline eHealth & 4.72 & 4.66 & 3.93 & $p<0.01$ \\
mHealth & 4.55 & 4.62 & 3.89 & $p<0.01$ \\
Both eHealth and mHealth & 4.58 & 4.62 & 3.86 & $p<\mathbf{0 . 0 1}$ \\
Standalone & 5.33 & 5,24 & 5.17 & $\boldsymbol{p} \mathbf{0 . 1}$ \\
\hline
\end{tabular}


Table 6 reports the output on a graded question related on the generalized optimism related to the general use of AI.

Table 6. Optimism on the AI use.

\begin{tabular}{ccccc}
\hline Optimism & $\begin{array}{c}\text { MSs } \\
\text { Score }\end{array}$ & $\begin{array}{l}\text { MPs } \\
\text { Score }\end{array}$ & $\begin{array}{l}\text { SASs } \\
\text { Score }\end{array}$ & $\begin{array}{c}\text { ANOVA } \\
p\end{array}$ \\
\hline $\begin{array}{c}\text { AI (All) } \\
\text { AI (people dealing with AI in the } \\
\text { workplace) }\end{array}$ & 4.58 & 4.57 & 4.53 & $p>\mathbf{0 . 1}$ \\
\hline
\end{tabular}

Data were successfully preliminarily tested for the normality using the Shapiro test.

With regards to the training (Table 2), the subjects passing the barrier showed a high degree (score $>$ TMV) in the three groups. However, the behavior was different in some cases. The ANOVA test highlighted some differences dependent on the different background: (a) in the case of informatics, where the SAS recorded a higher score; (b) in the case of technologies for biomedical apps, where both MPs and SASs showed a higher score.

We also included open-ended questions to investigate whether participants had direct experience (i.e., training on the job) in AI applied to the clinic. As far as MS is concerned, this can be represented, for example, by a direct experience of the clinical decision supported by AI. As for the MPs and SAS, this can be represented by direct activity on equipment equipped with AI systems as regards activities that can go from development to calibration and/or quality control. From these open questions, after classification and categorization, we found that a small percentage of respondents said they had or have such direct experience. A total of $14.3 \%$ of the MSs, $13.9 \%$ of the MPs, and $14.8 \%$ of the SASs had direct experience of training on the job. The trained on the job individuals showed a higher value of general optimism in the use of AI, uniform for the three groups (Table 6). With regards to the applications in medical imaging (Table 3), the subjects passing the barrier showed a high degree (score $>$ TMV) in the three groups. The behavior was uniform. The ANOVA test highlighted no differences in all the issues among the groups. It is here evident that even if the background is different-the MSs faced the diagnostic more; the MPS faced the imaging processes more; the SASs faced the technologies more-the diversity compensated among themselves.

With regards to the use of AI in applications in the general fields (excluding the medical imaging) (Table 4), the subjects passing the barrier showed a high degree (score $>$ TMV) in the three groups. However, the behavior was different in some cases. The ANOVA test highlighted some differences, dependent on the different background: (a) in the case of the more medical issues, risk assessment, therapy, and prevention where the MSs recorded a higher score; (b) in the case of quality control, both the MPs and SAS showed a higher score in this issue that is most related to the specific background. The opinion on the way of using/providing the AI (Table 5) is reported in consideration of the importance of the integration into the eHealth and mHealth [49]. With regards to this issue, the subjects passing the barrier showed a high degree (score > TMV) in the three groups, with a preference for the standalone approach. The preference for the standalone is probably due to the awareness on the exposition to the cyber risk. However, the behavior was different in some cases, where the SAS showed a lower score for the issues $m$ Health, eHealth, and both. This relates to the higher training in informatics (see above) that leads to higher awareness on the cyber risks when not applying AI in standalone.

\subsection{Key Considerations from the Submission Process and Suggestions from the Open Questions}

\subsubsection{Adhesion to the Survey}

This type of administration will be more and more widespread in the future. Analyzing the peculiarities and the outcome of the recruitment mechanisms is therefore of primary importance. The two administrations took place in different time intervals to allow the evaluation of the contributions to the total data collection. Two paths were followed in 
our study. The first one began in 2019 with the collection of availability in presence at congresses with the possibility of an oral interaction/discussion and subsequent sending with WhatsApp.

The second was without oral discussion and was based on peer-to-peer sending via WhatsApp. Figure 4 highlights how the greatest contribution to data collection came through the first method based on (traditional) oral communication. Figure 5 shows the percentages of adhesions with respect to each method. The results show that the first method had a surprisingly higher percentage of adhesion. This demonstrates how the oral communication made of the three verbal, para-verbal, and non-verbal components continues to maintain a greater grip than a communication made with chat only.
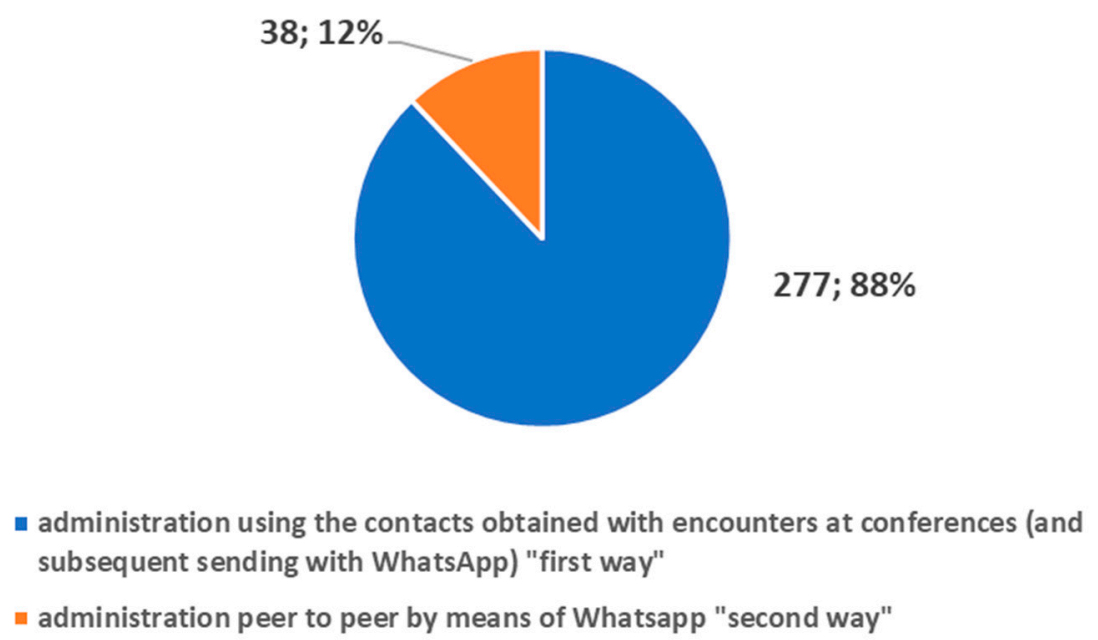

Figure 4. Contributions to the survey by the two different methods.

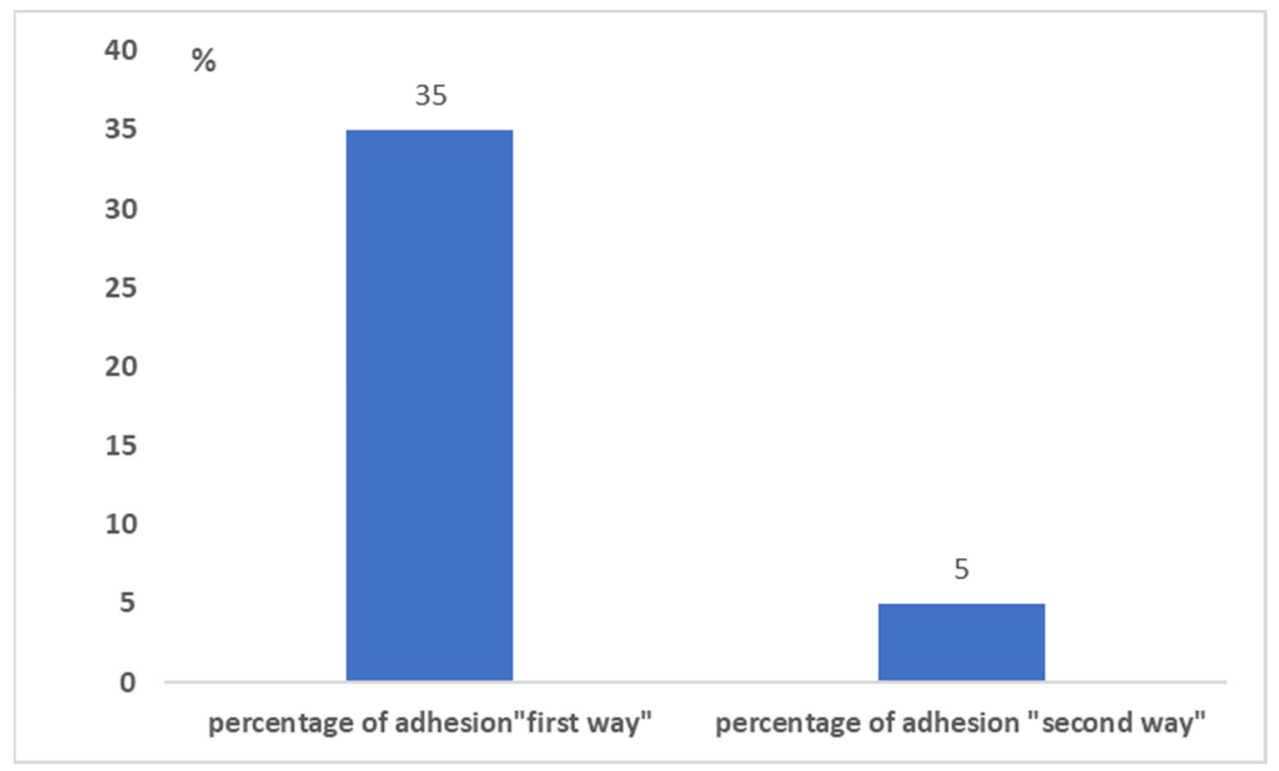

Figure 5. The percentage of adhesion to the survey by the two different methods.

\subsubsection{Outcome from the Open Question}

In the survey to question No. 13, we optionally offered the possibility of reporting comments and observations.

Twenty-one interviewed people reported an observation or comment. We analyzed the comments that highlighted critical issues and suggestions for improvement, and we carried out datamining, which was followed by categorization. 
Figure 6 reports the following points as important suggestions for improvement based on the order of the frequency of occurrence:

o to request the $\mathrm{CV}$ in a subsection with a series of targeted questions;

o to prepare a survey for each type of professional;

o to refine the survey within scientific societies;

o to offer a question/answer grid with very specific training aspects of AI.

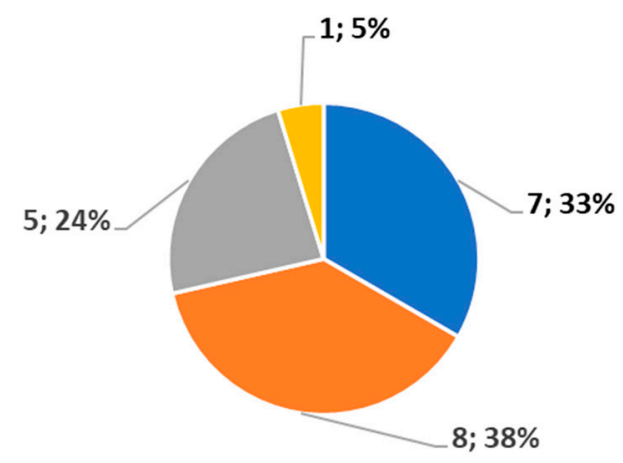

- to prepare a survey for each type of professional.

- To request the $\mathrm{CV}$ in a subsection with a series of targeted questions

- To refine the survey within scientific societies

- To offer a question / answer grid with very specific training aspects of Al

Figure 6. Suggestions for improvement with the obtained frequency of occurrence.

\section{Discussion}

We are undoubtedly about to face another important change in the world of digital radiology [14]: the introduction of AI in clinical practice. During the pandemic, the importance and potential of AI clearly emerged in two sectors of digital radiology: chest CT and chest radiography [15-18,43]. However, even before the pandemic, we were already talking about this phenomenon affecting the health domain, especially the sectors where the conversion to digital health has been heavy, such as the DR $[27,28]$, thanks to the DICOM standardization process. DICOM is the container of the information arranged into pixels and/or voxels after the process of image acquisition. The pixels and/or voxels used as AI input carry different information of the investigated biomedical target. The information in those elements is related to the physical process (X-rays, gamma rays, magnetic fields, ultrasounds, etc.). Three elements play an important role: (1) the physical process (PP), which depends on the physical fields used (X-rays, magnetic field, ultrasound, etc.); (2) the technological process $(T P)$, which concerns both the technologies for capturing information starting from the physical process, and the software implementation of AI-based algorithms; (3) the decision-making process (DP), which must consider the outcome from the TP based on a PP and the human decision based on medical knowledge functionally related to both the TP and PP.

It is for this reason that it is important that the experts of the DP, TP, and PP work are connected in the process of AI introduction and in the related investigations.

It should also be borne in mind that in addition to diagnostic imaging, other AI applications used for categorization into non-imaging problems $[9,27]$ (non-imaging categorization) were considered in the study. These range from risk analysis up to quality control. We also found it important to consider in the study how AI is delivered, whether it is delivered in standalone mode, or based on $m$ Health or eHealth [49]. In light of what has been illustrated above, we have decided to consider in the study the three figures of MSs, MPs, and SASs connected to $(1,2)$ to investigate the consensus and acceptance by means of an eS. From a general point of view, these three professional figures showed a high degree of acceptance 
of the introduction of AI both in imaging and in non-imaging applications, using both standalone and network modes ( $m$ Health or $e$ Health). Specifically, through a statistical assessment based on ANOVA, we were able to see a different way of approaching AI. This approach was uniform when considering AI applied to imaging. The approach was not uniform when considering the non-imaging applications and the delivery methods. Subjects with a background comprehending direct training on the job focused on AI showed the highest optimism. From a general point of view, the study highlights the usefulness of investigating the inclusion of $\mathrm{AI}$ through an $\mathrm{eS}$, the usefulness of doing so based on three categories of experts (MSs; MPs; SASs), and the general optimism in the introduction of AI in digital radiology.

The background plays an important role in relation to the approach to AI. In the scientific literature, various studies already involved radiologists (key figures in the clinical decision) to perform reader studies. In a certain sense, if we look at the study proposed on a direct application of AI [50] in its entirety, we realize that regarding the enhancement of $\mathrm{AI}$, the study we have proposed is in a complementary position. Our study directly focuses to the three involved professionals, having an active role in the flow from the tool design up to the decision [50]. Our study is in line with the studies based on surveys [37-47]; the submission of original surveys allows to obtain strategic information. In addition to similar studies, our study addressed the innovation of submitting the same survey to three key figures operating in the TP, PP, and DP. Furthermore, considering the needs that emerged from previous studies, our study proposed different survey schemes based on Likert/graded questions at six psychometric levels to have different quantitative outcomes, useful for categorizations.

A first scheme dealt with the educational, academic, and post-academic training aspects on modules relevant to the knowledge bases useful in this field.

A second scheme addressed the imaging aspects in detail, focusing on the different compatible DICOM tools used in DR.

The third scheme addressed the aspects of AI external to imaging but always relevant to the work flow (quality control, risk assessment, therapy and prevention) $[27,28]$.

A fourth scheme was dedicated to integration with eHealth and mHealth [49], strategic for addressing important aspects such as cybersecurity.

From a general point of view, the study differs from other initiatives in this direction [56-59]. Furthermore, it offers to the scholars a complementary contribution and therefore complementary results if compared to study based on surveys [58,59]. Our proposed survey (see Appendix A) comprehends 13 questions (23 if we consider that the Likert has submodules): (a) it is oriented to all three professions potentially involved, (b) it goes into detail in the application of AI in the different sectors of imaging with a specific Likert and by means of another Likert in the application of AI in the translational sectors of the health domain, and (c) it addresses aspects of network integration (standalone, mHealth, eHealth) important for the impact on software medical device and cybersecurity. We have used several modules detailing the choice questions, the open questions, the open large questions, and two modules used to give a psycho/sociometric assessment (now currently used in the life sciences): the graded questions and the Likert. In addition, in our survey, there was also the possibility of supplementing the demographic information (including training) and work activity with two specific open questions, one open large question dedicated to the insertion of the $\mathrm{CV}$, and one open question dedicated to the description of one's own working activity.

The two surveys in $[58,59]$ are in turn complementary; they are each dedicated to a specific professional figure and with different focuses.

The survey reported in [58] concerns a national audience, is focused on the MSs, and is made up of 13 questions: 4 dedicated to demographic aspects (age, region, activity, position and job site), 3 dedicated to interaction with AI (tasks by AI, advantages, issues), 3 dedicated to implications (ethical problems, risk of job loss, needs of policies), and other questions in complement, such as the opinion on the definition of AI. 
The other survey [59] concerns an international audience, is dedicated to the figure of the MP, and consists of 25 questions. The first eight deal with the training aspects, the involvement in AI projects and with the activities and the opinion on the introduction of AI. Questions 9 to 17 all concern the collection of educational interests in a specific way and the opinions on the integration of the $\mathrm{CV}$ in future activities. An open question (number 18 ) is free. The final questions are all focused on demographics.

Our survey was submitted through two channels, both electronic (one of which, however, was also based on a preliminary in-person presentation of the initiative), which were evaluated. Part of the analysis was dedicated to the observations and criticalities that emerged, as well as specifically collected.

Both the surveys reported in [58,59] were administered with purely electronic methods, and there was no comparison between different modalities. They did not use graded questions and Likert questions. Furthermore, the critical issues to be addressed to improve these initiatives were not collected from both the surveys.

As regards the dissemination of the survey, our study shows that a preliminary contact in presence (followed by an electronic transmission) improves the participation rate. This suggests for the future to address these initiatives by preceding them by preliminary faceto-face meetings (for example, in focus groups or congresses). Regarding suggestions for improvement and development, it should be noted that those proposals that have had a frequency greater than 1 push towards a structured request in a grid of the $\mathrm{CV}$, a specialization of the survey for the different professionals, and a refinement in scientific societies.

Considering these observations and what has emerged, the continuation of these initiatives in both a specialized and federated way is certainly desirable. It is hoped that the AI will be an opportunity to give birth to scientific federations that allow for in-depth initiatives in both a specific and confederate way.

\section{Conclusions}

The introduction of AI into clinical practice is now an unstoppable process that will take this discipline from research to routine use. Many professionals from now to the future will be involved, and it will be necessary to provide for targeted consensus actions to issue appropriate recommendations. Guidelines, TA reports, and consensus conferences, spread by scientific societies in the sector, for example, will in the future also use approaches based on surveys that scholars are currently developing.

Initiatives aimed at creating position papers in this area will be more and more frequent and will involve more and more teams of professionals, as in [56], where medical physics and radiologists have worked. Both national [57,58] and international [59] scientific societies could play an important role in the improvement and dissemination of these surveys, which could play a strategic role in monitoring the topic. It will also be important that scientific societies representing the different actors work as a team in initiatives that could possibly lead to stable and standardized international monitoring actions.

Author Contributions: Conceptualization, D.G.; methodology, D.G. and F.D.B.; software, D.G. and L.M.; validation, D.G., G.E. and F.D.B.; formal analysis, All; investigation, All; resources, not applicable; data curation, D.G. and L.M.; writing-original draft preparation, D.G.; writing-review and editing, All; visualization, All; supervision, D.G.; project administration, D.G. and L.M.; funding acquisition, not applicable. All authors have read and agreed to the published version of the manuscript.

Funding: This research received no external funding.

Institutional Review Board Statement: Not applicable.

Informed Consent Statement: Not applicable.

Data Availability Statement: Not applicable.

Conflicts of Interest: The authors declare no conflict of interest. 


\section{Abbreviations}

$\begin{array}{ll}\text { Acronym } & \text { Description } \\ \text { AI } & \text { Artificial intelligence } \\ \text { CT } & \text { Computerized tomography } \\ \text { MP } & \text { Medical physicist } \\ \text { SAS } & \text { Specialists of applied sciences } \\ \text { MS } & \text { Medical specialist } \\ \text { DICOM } & \text { Digital imaging and communications in medicine } \\ \text { DR } & \text { Digital radiology } \\ \text { TA } & \text { Technology assessment } \\ \text { HTA } & \text { Health technology assessment } \\ \text { CER } & \text { Comparative effectiveness research } \\ \text { PCP } & \text { Primary care provider } \\ \text { TP } & \text { Technological process } \\ \text { TMV } & \text { Theorical mean value } \\ \text { PP } & \text { Physical process } \\ \text { DP } & \text { Decision-making process } \\ \text { ANOVA } & \text { Analysis of variance } \\ \text { eHealth } & \text { Electronic health } \\ \text { mHealth } & \text { Mobile health } \\ & \end{array}$

\section{Appendix A}

Survey on the introduction of artificial intelligence (AI) in digital radiology

\section{* Obbligatoria}

1. The data will be used anonymously for a study on this issue. Agree to participate *

No

$\mathrm{Y}$ Yes

2. This survey is dedicated to professionals involved in digital radiology:to participate you must at least fall into one of the following three cases: *

a) I had training (seminars, courses, congresses, etc.) in the university field on issues relating to artificial intelligence in this area which allows me to undertake an opinion survey on it introdution and impact.

b)) I had training (seminars, courses, congresses, etc.) in the workplace on issues relating to artificial intelligence in this area that allows me to undertake an opinion survey on its introduction and impact.

c) I had an on-the-job training in the workplace on issues related to artificial intelligence in this area that allows me to deal with an opinion survey on its introduction and impact

d) I do not fall into any of the above cases

\section{Sex * \\ Male}

Fernale
4. Age

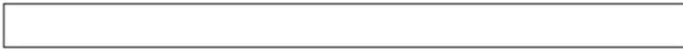

5. Enter your CV here anonymously *

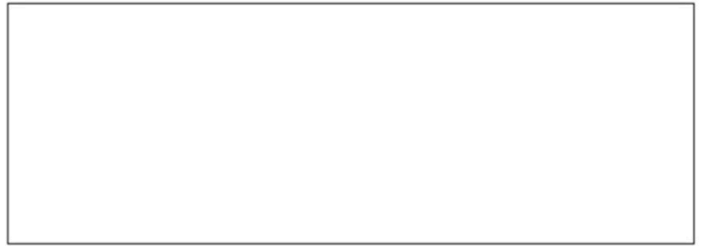

6. Enter your Al training level here *

$1=\min ; 6=\max$

\begin{tabular}{|c|c|c|c|c|}
\hline & 1 & 2 & 3 & 4 \\
\hline $\begin{array}{l}\text { Artificial Intelligence (in } \\
\text { general) }\end{array}$ & $\mathrm{O}$ & $\mathrm{O}$ & $\mathrm{O}$ & $\mathrm{O}$ \\
\hline Al (informatics) & 0 & 0 & 0 & 0 \\
\hline Al (medical imaging) & $\mathrm{O}$ & 0 & 0 & 0 \\
\hline $\begin{array}{l}\text { Technologies for } \\
\text { biomedical Apps }\end{array}$ & 0 & 0 & 0 & 0 \\
\hline
\end{tabular}

12/18/2021

Figure A1. An example of the survey (first print screen). 




Figure A2. An example of the survey (second print screen).

\section{References}

1. Thrall, J.H. Teleradiology. Part I. History and clinical applications. Radiology 2007, 243, 613-617. [CrossRef] [PubMed]

2. Thrall, J.H. Teleradiology. Part II. Limitations, risks, and opportunities. Radiology 2007, 244, 325-328. [CrossRef] [PubMed]

3. Reponen, J. Teleradiology —Changing Radiological Service Processes from Local to Regional, International and Mobile Environment; University of Oulu: Oulu, Finland, 2010.

4. Wootton, R. Telemedicine: A cautious welcome. BMJ 1996, 313, 1375-1377. [CrossRef]

5. Giansanti, D. Teleradiology Today: The Quality Concept and the Italian Point of View. Telemed. E-Health 2017, 23, 453-455. [CrossRef] [PubMed]

6. Orlacchio, A.; Romeo, P.; Inserra, M.C.; Grigioni, M.; Giansanti, D. Guidelines for Quality Assurance and Technical Requirements in Teleradiology; English Translation and Revision of Rapporti ISTISAN 10/44, Rapporti ISTISAN 13/38; Istituto Superiore di Sanità: Roma, Italy, 2013; pp. 1-33.

7. Ruotsalainen, P. Privacy and security in teleradiology. Eur. J. Radiol. 2010, 73, 31-35. [CrossRef] [PubMed]

8. Giansanti, D. Diagnostic Imaging and E-Health: Standardization, Experiences and New Opportunities; Rapporti ISTISAN 17/10; Istituto Superiore di Sanità: Roma, Italy, 2017; pp. 1-60.

9. Giansanti, D. Diagnostics Imaging and M-Health: Investigations on the Prospects of Integration in Cytological and Organ Diagnostics; Rapporti ISTISAN 20/1; Istituto Superiore di Sanità: Roma, Italy, 2019; pp. 1-66.

10. Canadian Association of Radiologists. CAR Standards for Teleradiology; Canadian Association of Radiologists: Ottawa, ON, Canada, 2008.

11. American College of Radiology. ACR Standard for Teleradiology; ACR: Reston, VA, USA, 2002.

12. Teleradiology. Merrian-Webster Medical Dictionary Online. Available online: www.merriamwebster.com/medical/teleradiology (accessed on 30 September 2013).

13. Dicom, Digital Imaging and Communication in Medicine. Available online: https://www.dicomstandard.org/ (accessed on 9 January 2022). 
14. Giansanti, D. The Artificial Intelligence in Digital Pathology and Digital Radiology: Where Are We? Healthcare 2020, 9, 30. [CrossRef]

15. Alsharif, M.H.; Alsharif, Y.H.; Yahya, K.; Alomari, O.A.; Albreem, M.A.; Jahid, A. Deep learning applications to combat the dissemination of COVID-19 disease: A review. Eur. Rev. Med. Pharmacol. Sci. 2020, 24, 11455-11460.

16. Ozsahin, I.; Sekeroglu, B.; Musa, M.S.; Mustapha, M.T.; Uzun Ozsahin, D. Review on Diagnosis of COVID-19 from Chest CT Images Using Artificial Intelligence. Comput. Math. Methods Med. 2020, 2020, 9756518. [CrossRef]

17. Pham, T.D. Classification of COVID-19 chest X-rays with deep learning: New models or fine tuning? Health Inf. Sci. Syst. 2020, 9, 2. [CrossRef]

18. Liang, H.; Guo, Y.; Chen, X.; Ang, K.L.; He, Y.; Jiang, N.; Du, Q.; Zeng, Q.; Lu, L.; Gao, Z.; et al. Artificial intelligence for stepwise diagnosis and monitoring of COVID-19. Eur. Radiol. 2022, 1-11, Epub ahead of print. [CrossRef]

19. Stevenson, A. Oxford Dictionary of English, 3rd ed.; Oxford University Press: Oxford, UK, 2010.

20. Hsiang, C.W.; Lin, C.; Liu, W.C.; Lin, C.S.; Chang, W.C.; Hsu, H.H.; Huang, G.S.; Lou, Y.S.; Lee, C.C.; Wang, C.H.; et al. Detection of left ventricular systolic dysfunction using an artificial intelligence-enabled chest X-ray. Can. J. Cardiol. 2022, Epub ahead of print. [CrossRef]

21. Tajik, A.J. Machine Learning for Echocardiographic imaging: Embarking on another incredible journey. J. Am. Coll. Cardiol. 2016, 68, 2296-2298. [CrossRef]

22. Krittanawong, C.; Zhang, H.; Wang, Z.; Aydar, M.; Kitai, T. Artificial intelligence in precision cardiovascular medicine. J. Am. Coll. Cardiol. 2017, 69, 2657-2664. [CrossRef] [PubMed]

23. Zhang, J.; Gajjala, S.; Agrawal, P.; Tison, G.H.; Hallock, L.A.; Beussink-Nelson, L.; Deo, R.C. Fully automated echocardiogram interpretation in clinical practice. Circulation 2018, 138, 1623-1635. [CrossRef] [PubMed]

24. Rodriguez-Ruiz, A.; Lång, K.; Gubern-Merida, A.; Broeders, M.; Gennaro, G.; Clauser, P.; Helbich, T.H.; Chevalier, M.; Tan, T.; Mertelmeier, T.; et al. Stand-Alone Artificial Intelligence for Breast Cancer Detection in Mammography: Comparison With 101 Radiologists. J. Natl. Cancer Inst. 2019, 111, 916-922. [CrossRef] [PubMed]

25. Bertini, F.; Allevi, D.; Lutero, G.; Montesi, D.; Calzà, L. Automatic Speech Classifier for Mild Cognitive Impairment and Early Dementia. ACM Trans. Comput. Healthc. 2022, 3, 1-11. [CrossRef]

26. Mak, K.K.; Pichika, M.R. Artificial intelligence in drug development: Present status and future prospects. Drug Discov. Today 2019, 24, 773-780. [CrossRef]

27. Jalal, S.; Nicolaou, S.; Parker, W. Artificial Intelligence, Radiology, and the Way Forward. Can. Assoc. Radiol. J. 2019, 70, 10-12. [CrossRef]

28. European Society of Radiology (ESR). What the radiologist should know about artificial intelligence-An ESR white paper. Insights Imaging 2019, 10, 44. [CrossRef]

29. Regulation (EU) 2017/745 of the European Parliament and of the Council of 5 April 2017 on Medical Devices, Amending Directive 2001/83/EC, Regulation (EC) No 178/2002 and Regulation (EC) No 1223/2009 and Repealing Council Directives 90/385/EEC and 93/42/EEC.2017. Available online: https:/ / eur-lex.europa.eu/legal-content/EN/TXT/HTML/?uri=CELEX: 32017R0745\&from $=$ IT (accessed on 25 November 2021).

30. Giansanti, D. Cybersecurity and the Digital-Health: The Challenge of This Millennium. Healthcare 2021, 9, 62. [CrossRef]

31. Evidence-Based Medicine Guidelines. Available online: https://www.ebm-guidelines.com/dtk/ebmg/home (accessed on 9 January 2022).

32. Luce, B.R.; Drummond, M.; Jönsson, B.; Neumann, P.J.; Schwartz, J.S.; Siebert, U.; Sullivan, S.D. EBM, HTA, and CER: Clearing the confusion. Milbank Q. 2010, 88, 256-276. [CrossRef]

33. McGlynn, E.A.; Kosecoff, J.; Brook, R.H. Format and conduct of consensus development conferences. Multi-nation comparison. Int. J. Technol. Assess. Health Care 1990, 6, 450-469. [CrossRef]

34. Eddy, D.M. Evidence-Based Medicine: A Unified Approach. Health Affairs 2005, 24, 9-17. [CrossRef] [PubMed]

35. National Library of Medicine. Available online: https://pubmed.ncbi.nlm.nih.gov $/$ ?term $=\% 28$ acceptance $\% 29+A N D+\% 2$ 8artificial+intelligence $\% 5 B$ Title $\% 2 F A b s t r a c t \% 5 D \% 29+A N D+R a d i o l o g y \& s o r t=d a t e \& s i z e=200$ (accessed on 9 January 2022).

36. National Library of Medicine. Available online: https://pubmed.ncbi.nlm.nih.gov $/$ ?term= $\% 28 \% 28$ consensus $\% 29+$ AND + \%28artificial+intelligence $\% 5$ BTitle $\% 2$ FAbstract $\% 5$ D $\% 29 \% 29+A N D+\% 28$ radiology $\% 5 B T i t l e \% 2 F A b s t r a c t \% 5 D \% 29 \&$ sort=date\& size $=200$ (accessed on 9 January 2022).

37. Lennartz, S.; Dratsch, T.; Zopfs, D.; Persigehl, T.; Maintz, D.; Hokamp, N.G.; Dos Santos, D.P. Use and Control of Artificial Intelligence in Patients Across the Medical Workflow: Single-Center Questionnaire Study of Patient Perspectives. J. Med. Internet Res. 2021, 23, e24221. [CrossRef] [PubMed]

38. Zhang, Z.; Citardi, D.; Wang, D.; Genc, Y.; Shan, J.; Fan, X. Patients' perceptions of using artificial intelligence (AI)-based technology to comprehend radiology imaging data. Health Inform. J. 2021, 27, 14604582211011215. [CrossRef]

39. Ongena, Y.P.; Haan, M.; Yakar, D.; Kwee, T.C. Patients' views on the implementation of artificial intelligence in radiology: Development and validation of a standardized questionnaire. Eur. Radiol. 2020, 30, 1033-1040. [CrossRef] [PubMed]

40. Hendrix, N.; Hauber, B.; Lee, C.I.; Bansal, A.; Veenstra, D.L. Artificial intelligence in breast cancer screening: Primary care provider preferences. J. Am. Med. Inform. Assoc. 2021, 28, 1117-1124. [CrossRef]

41. Abuzaid, M.M.; Elshami, W.; McConnell, J.; Tekin, H.O. An extensive survey on radiographers from the Middle East and India on artificial intelligence integration in radiology practice. Health Technol. 2021, 11, 1045-1050. [CrossRef] 
42. Abuzaid, M.M.; Tekin, H.O.; Reza, M.; Elhag, I.R.; Elshami, W. Assessment of MRI technologists in acceptance and willingness to integrate artificial intelligence into practice. Radiography 2021, 27, S83-S87. [CrossRef]

43. Giansanti, D.; Rossi, I.; Monoscalco, L. Lessons from the COVID-19 Pandemic on the Use of Artificial Intelligence in Digital Radiology: The Submission of a Survey to Investigate the Opinion of Insiders. Healthcare 2021, 9, 331. [CrossRef] [PubMed]

44. Abuzaid, M.M.; Elshami, W.; Tekin, H.; Issa, B. Assessment of the Willingness of Radiologists and Radiographers to Accept the Integration of Artificial Intelligence into Radiology Practice. Acad. Radiol. 2020, 29, 87-94. [CrossRef] [PubMed]

45. Alelyani, M.; Alamri, S.; Alqahtani, M.S.; Musa, A.; Almater, H.; Alqahtani, N.; Alshahrani, F.; Alelyani, S. Radiology Community Attitude in Saudi Arabia about the Applications of Artificial Intelligence in Radiology. Healthcare 2021, 9, 834. [CrossRef] [PubMed]

46. European Society of Radiology (ESR). Impact of artificial intelligence on radiology: A EuroAIM survey among members of the European Society of Radiology. Insights Imaging 2019, 10, 105. [CrossRef] [PubMed]

47. Galán, G.C.; Portero, F.S. Medical students' perceptions of the impact of artificial intelligence in Radiology. Radiologia 2021, in press [CrossRef]

48. Aldosari, B. User acceptance of a picture archiving and communication system (PACS) in a Saudi Arabian hospital radiology department. BMC Med. Inform. Decis. Mak. 2012, 12, 44. [CrossRef]

49. Moss, R.J.; Süle, A.; Kohl, S. eHealth and mHealth. Eur. J. Hosp. Pharm. 2019, 26, 57-58. [CrossRef] [PubMed]

50. Shan, H.; Padole, A.; Homayounieh, F.; Kruger, U.; Khera, R.D.; Nitiwarangkul, C.; Kalra, M.K.; Wang, G. Competitive performance of a modularized deep neural network compared to commercial algorithms for low-dose CT image reconstruction. Nat. Mach. Intell. 2019, 1, 269-276. [CrossRef]

51. Moher, D.; Altman, D.G.; Schulz, K.F.; Simera, I.; Wager, E. (Eds.) Guidelines for Reporting Health Research: A User's Manual Available online: https:/ / onlinelibrary.wiley.com/doi/abs/10.1002/9781118715598.ch20 (accessed on 9 January 2022).

52. Ministero Della Salute Rivede Elenco Società Scientifiche per Stesura Linee Guida. 41 Società in Più. Available online: http:/ / www.aiponet.it/news/104-ufficio-stampa/2149-ministero-della-salute-rivede-elenco-societa-scientifiche-per-stesuralinee-guida-41-societa-in-piu.html (accessed on 9 January 2022).

53. Federazione Delle Società Medico-Scientifiche Italiane. Available online: https:/ / portale.fism.it/ (accessed on 9 January 2022).

54. Federazione Delle Associazioni Scientifiche dei Tecnici di Radiologia. Available online: https://www.associazionefaster.org/ (accessed on 9 January 2022).

55. Federazione Delle Associazioni Scientifiche e Tecniche. Available online: https://fast.mi.it/chi-siamo/ (accessed on 9 January 2022).

56. Thomassin-Naggara, I.; Balleyguier, C.; Ceugnart, L.; Heid, P.; Lenczner, G.; Maire, A.; Séradour, B.; Verzaux, L.; Taourel, P. Conseil National Professionnel de la Radiologie et Imagerie Médicale (G4). Artificial intelligence and breast screening: French Radiology Community position paper. Diagn. Interv. Imaging 2019, 100, 553-566. [CrossRef]

57. Avanzo, M.; Trianni, A.; Botta, F.; Talamonti, C.; Stasi, M.; Iori, M. Artificial Intelligence and the Medical Physicist: Welcome to the Machine. Appl. Sci. 2021, 11, 1691. [CrossRef]

58. Coppola, F.; Faggioni, L.; Regge, D.; Giovagnoni, A.; Golfieri, R.; Bibbolino, C.; Miele, V.; Neri, E.; Grassi, R. Artificial intelligence: Radiologists' expectations and opinions gleaned from a nationwide online survey. Radiol. Med. 2021, 126, 63-71. [CrossRef]

59. Diaz, O.; Guidi, G.; Ivashchenko, O.; Colgan, N.; Zanca, F. Artificial intelligence in the medical physics community: An international survey. Phys. Med. 2021, 81, 141-146. [CrossRef] 